433 STUDIES IN NECROTIZING ENTEROCOLITIS (NEC): EFFECTS Henley, Frederick Adams, Eugene Ainbender, Edwin 0 . Brown Bruce Hanna, Catherine M.P. Kierney and John Silverio. Mt. Sinal School of Med1cine, Departments of Pedtatrics \& Microbology, New York, and Wyeth Laboratories, Ph1ladelphia.

NEC appears to be of multifactorial origin. Bacteria may be 1 mportant as shown by one study in wh1ch $67 \%$ of patients with NEC harbored Klebstella in the GI tract. That organism produces enterotoxins and endotoxins, and invades the systemic circulation readily when the gut mucosa is compromised. Human milk may protect against NEC by altering the fecal flora as 1 t does against neonatal diarrhea (Gyorgi). Previously we found no difference in quantities of $s$ tool endotoxin in full-term infants fed fresh breast milk or a proprietary formula; with increased feedings there were more GI microorganisms and endotoxin production.

We have now studied the GI bacterial flora of neonates in an ICU who were fed Enfamil and a humantzed formula (SMA). Infants between 1,500 and $2,250 \mathrm{gms}$ at birth were assigned weight groups differing by $250 \mathrm{gms}$, and chosen randomly to be fed 1 of the 2 formulas. Infants in distress or receiving antibiotics were excluded. Klebsiella appeared more of ten in the stools of infants fed Enfamil ( $p<0.05)$; Bacteroides fraglils was detected more of ten with SMA $(p>0.05)$. Both formulas supported growth of $E$. foll and clostridium equally.

The formulas used in this study affected the microbial flora $\mathrm{p} f$ the nursery population. Outbreaks of NEC and the course of the disease may be influenced by the type of formula fed as well

\title{
434 ESOPHAGITIS AND LOWER ESOPHAGEAL SPHINCTER PRESSURE
}

G. Johnson. University of Utah, College of Medicine, Departments of Pediatrics and Surgery, Salt Lake City, Utah.

Patients with gastroesophageal reflux (GER) frequently have a decreased lower esophageal sphincter (LES) pressure that increases after surgery, although variable results have been noted in children. LES pressures were measured in 80 patients $>3$ months of age with symptomatic GER and in 20 control patients. The esophageal probe was a triple lumen catheter perfused at a rate of $1.5 \mathrm{ml}$ per min. Patients were classified as having severe esophagitis if they had stricture, hematemesis or friable esophageal mucosa at esophagoscopy. Normal patients had mean \pm SEM pressures of $11.4+0.9 \mathrm{~mm} \mathrm{Hg}$ while 20 patients with severe esophagitis had $L E \bar{S}$ pressures of $4.3+0.8 \mathrm{~mm} \mathrm{Hg}(p<.001)$ Symptomatic GER patients without esophagitis $(N=60)$ had LES pressures of $11.6 \pm 0.9 \mathrm{~mm} \mathrm{Hg}$. In the 10 esophagitis patients with pre and postoperative LES measurements, the average change was $+2 \mathrm{~mm} \mathrm{Hg}$, and the mean postoperative LES pressure was not different from controls. Patients without esophagitis who ultimately required surgery had LES pressures that were not different from controls, and the average change in LES pressure in the $20 \mathrm{pa}-$ tients with pre and postoperative studies was $-0.5 \mathrm{~mm} \mathrm{Hg}$. A low LES pressure with a postoperative increase in pressure was noted only when severe esophagitis accompanied the symptomatic GER. The low LES pressures frequently noted in GER patients may be a result of esophageal inflammation rather than the cause of GER.

435 B ILE AC ID (BA) TRANS PORT DEFECT: ONE CAUSE OF REFRACTORY INFANT ILE DIARRHEA (R.I.D.). JE HEUBI, WB BALI-

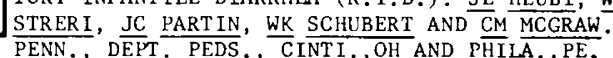

CINTI. AND PENN., DEPT. PEDS. , CINTI., OH AND PHILA., PE. alimentation for 27 months. Watery diarrhea (mean fecal wt. 542 gm.) and steatorrhea (mean fecal fat $15.4 \mathrm{gm}$./day), persistently low serum cholesterol averaging $72 \mathrm{mg} \%$ and vitamin $\mathrm{B}_{12}$ malabsorption have been present since birth. Small intestinal morphology is normal by lipid histochemical and electron microscopic examination. Surgical exploration revealed normal anatomy. Mean intraluminal $B A$ after meal stimulation are $3.70 \mathrm{mM} / \mathrm{L}$ for the first meal and $1.01 \mathrm{mM} / \mathrm{L}$ for the third meal of the day. Fecal excretion of oral cholic-carboxyl- $14 \mathrm{C}$ at 20 months was $58 \%$ for the first 24 hours vs. $4.8 \% \pm 1.0$ in 5 normal controls. Mean fecal aqueous supernatant BA are $1102 \mu \mathrm{M} / 24$ hours vs. $100.2 \mu \mathrm{M} \pm$ $35.3 / 24$ hours in 5 normal controls. Cholic acid kinetic studies at 64 and 68 months revealed a fractional turnover rate (FTR) of 1.78 and 2.55 days $^{-1}$, pool size of 21.8 and $49.1 \mathrm{mg} / \mathrm{m}^{2}$ and synthet ic rate was 38.9 and $125.2 \mathrm{mg} / \mathrm{m}^{2} /$ day respectively. At $64 \mathrm{mos}$. the chenodeoxycholic pool size was $48.2 \mathrm{mg} / \mathrm{m}^{2}$, FTR was 0.82 days $^{-1}$ and the synthetic rate was $39.4 \mathrm{mg} / \mathrm{m}^{2} /$ day. No secondary BA were present. Very rapid BA turnover, contracted pool sizes, low intraluminal bile salt concentrations, elevated fecal bile salts, absence of secondary $B A$ and abnormal $B_{12}$ absorption strungly suggests that failure of $B A$ reabsorption and consequent BA deficiency cause this child's R.I.D, and constitute a specific congenital metabolic defect.

436 SMALL INTESTINAL FATTY ACID (FA) ESTER IF ICATION IN IN FANT AND CHILD MUCOSAL BIOPSIES. JE HEUBI, CM MCGRAW, JC PART IN AND WK SCHUBERT. UNIV.CINTI. DEPT, PEDS,CINTI Uptake (U) and esterification (E) of oleic acid was studied i ntact intestinal mucosa of infants and children. Crosby-Kugler intestinal biopsy specimens were incubated in vitro in Krebs-Ringer buffer (pH 6.3), $0.01 \mathrm{mM}$ glucose, $2.4 \mathrm{mM}$ Na taurodeoxycholate $0.06 \mu \mathrm{M}$ oleic $-1-14 \mathrm{C}, 0.54 \mu \mathrm{M}$ oleic acid and $0.3 \mu \mathrm{M}$ glycero-2-mon opalmitate at 370 , lipid extracted, separated by thin layer chromatography and counted in a scintillation spectrometer. All specimens were examined histologically. 26 patients (age 4 mos. to $14 \mathrm{yrs}$ ) and 1 adult were studied in 4 groups. Group 1 , functional diarrhea with normal mucosa, Group 2, treated celiacs and

relatives, Group 3, patients with mucosal disease and Group 4,
patients with intraluminal bile acid deficiencies were studied:

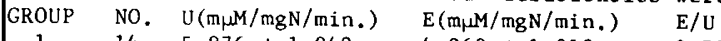

$\begin{array}{lrlll}1 & 14 & 5.876 \pm 1.942 & 4.060 \pm 1.010 & 0.71 \pm .14 \\ 2 & 5 & 3.502 \pm 1.143 * & 1.839 \pm 0.562+ & 0.53 \pm .04^{*} \\ 3 & 5 & 2.871 \pm 0.813 * * & 1.563 \pm 0.323+ & 0.54 \pm .07 * \\ 4 & 3 & 3.778 \pm 0.920 & 2.634 \pm 0.618^{*} & 0.70 \pm .01\end{array}$

\section{$p<0.05, * * p<0.0 \overline{1}, \quad+p<0.001$ vs Group I}

o significant difference in $E$ or $U$ with age was seen in Group 1. A simple reliable method to measure FA uptake and esterification in very small quantities of mucosa is presented. FA esterification, uptake and $E / U$ were significantly depressed in mucosal Hisease and treated celiacs and their relatives. Application of the principles of this technique to other areas of mucosal metabolism may enable definition of previously undefined diarrheal

SERUM 25-HYDROXY-VITAMIN D (25-OHD) CONCENTRATIONS AND BONE HISTOLOGY IN SUDDEN INFANT DEATH SYNDROME (SIDS). Laura S. Hillman, Steven L. Teitelbaum, and John G. Haddad (Spon. by R.E. Hillman), Washington Univ. School of Med., St. Louls Children's Hosp. Dept. of Ped. and Jewish Hosp. of St. Louis, Dept. of Med., St. Louis, MO

Based on an increased winter incidence, less time outside, increased "microscopic rickets," and a speculation that hypocalcemia and laryngospasm are a terminal event, the possibility of vitamin $D$ deficlency in SIDS has been raised. Further, evidence of growth arrest in costochondral junctions has been reported in $90 \%$ of unexplained infant deaths. Post mortem serum samples and sixth ribs were collected from 23 SIDS and 7 control infants. Ribs were immediately placed in Millonig's fixative and processed without decalcification. The mean \pm S.D. of serum $25-0 \mathrm{HD}$ in the SIDS cases was $21.0 \pm 7.9 \mathrm{ng} / \mathrm{ml}$, control post mortem samples were $13.2 \pm 9.3 \mathrm{ng} / \mathrm{ml}$. The mean of the SIDS is well above hypocalcemic or rachitic ranges $(<6 \mathrm{ng} / \mathrm{ml})$ and did not differ from normal adults $(24 \pm 9.7 \mathrm{ng} / \mathrm{ml})$ or 39 living premature and SGA infants at 3 months of age $(26 \pm 9.9 \mathrm{ng} / \mathrm{m} 1)$. Serum calcium values were within physiological ranges (mean \pm S.D. SIDS $9.34 \pm$ $1.8 \mathrm{mg} \%$, control $9.22 \pm 1.85 \mathrm{mg} \%$ ). Of currently analyzed rib specimens, normal histology with normal costochondral junctions and normal mineralization has been found. Thus, vitamin $D$ deficiency per se, as reflected by serum 25-OHD, can be ruled out as a cause of a SIDS. We have not been able thus far to confirm the finding of postnatal growth abnormalities in rib cartilage and bone in SIDS.

438 AGE AND SPECIES-RELATED ADHERENCE OF VIBRIO CHOLERAE SMALL INTESTINE AND ISOLATED ENTEROCYTES. MOShe University of California, Department of Pediatrics, San Francis We have previously reported avid, mannose-specific binding of E. Coli to immature compared with mature intestinal mucosa in rats and rabbits (Clin. Res. 25:469A, 1977). Therefore, agedependence and specificity of intestinal adherence of vibrio cholerae (VC) in developing rats and rabbits was investigated in mucosal preparations and in isolated enterocytes incubated with radiolabeled Vc and 18 a -methyl mannose (MM), mannan (M), or fucose $(F)$. (Controls $=18$ sucrose or dextran). Non-adherent bacteria were separated by ultrafiltration. Adherence of Vc was maximal 6-12 days after birth (adherence $=208$ ). A 60-fold decline in binding occurred at weaning. Binding of $\mathrm{Vc}_{c}$ in jejunum and ileum of pre-weanling rats was inhibited 90-1008 with $M, 60-$ 758 with F, and 55-658 wtih MM. Weaned and adult rats were resistant to inhibition. In contrast, binding of Vc by rabbit fetal, newborn and adult mucosa and enterocytes was equivalent. as efficient as in unweaned rats, and inhibited by $M$ and $F(60-$ $808)$. Conclusions: Intestinal binding of $\mathrm{VC}$ is dependent upon sugar-specific mechanisms present permanently in rabbits, but disappearing in rats at weaning. These binding patterns correlate rats and rabbits to cholera, and suggest that mucosal adherence may play a role in pathogenicity of $\mathrm{V}_{c}$. 